\title{
Avaliação de Pastagem Diferida de Brachiaria decumbens Stapf: 1. Características Químico-Bromatológicas da Forragem Durante a Seca ${ }^{1}$
}

\section{Eduardo Destéfani Guimarães Santos ${ }^{2}$, Mário Fonseca Paulino ${ }^{3}$, Domingos Sávio Queiroz ${ }^{4}$, Sebastião de Campos Valadares Filho ${ }^{5}$, Dilermando Miranda da Fonseca ${ }^{5}$, Rogério de Paula Lana ${ }^{5}$}

\begin{abstract}
RESUMO - Verificaram-se, durante o período seco, as composições químico-bromatológicas da forragem colhida em pastagem diferida de Brachiaria decumbens por dois métodos, forragem total (FT) e extrusa (EXT); as composições químico-bromatológicas; e as frações de proteína e carboidratos dos componentes folha verde (FV), caule verde (CV), folha seca (FS) e caule seco (CS). A FT apresentou proteína bruta (PB) inferior a 2,5\%; a fibra em detergente neutro (FDN), superior a 78\%; a lignina, superior a $8,7 \%$ na MS; e a digestibilidade in vitro da matéria seca (DIVMS), de 43,5\%. A EXT apresentou maior DIVMS e maiores teores de PB, proteína insolúvel em detergente neutro e ácido, cinzas e fósforo e menores teores de fibras, carboidratos totais (CHT) e magnésio, quando comparado com FT. Verificaram-se maiores DIVMS e teores de PB, carboidratos não fibrosos (CNF), fósforo e potássio no componente FV e maiores teores de CHT e FDN nos componentes CV, FS e CS. Observaram-se altos valores da fração A da PB nos componentes FV e CV, baixos valores em FS e CS e altos valores da fração C da PB em CV, FS e CS. As concentrações das frações potencialmente digestíveis da $\mathrm{PB}$, com exceção da fração $\mathrm{B}_{1}$, e de CNF, correlacionaram-se com o teor protéico nos componentes FV, CV, FS e CS. Em relação aos CHT, verificaram-se baixos valores de CNF e altos da fração C nos componentes CV, FS e CS.
\end{abstract}

Palavras-chave: capim-braquiária, pastagem tropical, qualidade da pastagem

\section{Evaluation of a Signalgrass (Brachiaria decumbens Stapf) Postponed Pasture. 1. Quality of Herbage During the Dry Season}

\begin{abstract}
The chemical-bromatological characteristics of forage sampled for two methods, available herbage (AH) and extrusa (EXT), and green leaf (GL), green stem (GS), dead leaf (DL) and dead stem (DS) dry matter (DM) components were evaluated in the Signalgrass postponed pasture, during the dry season, from July to October 1997. Protein and carbohydrate fractions of the Cornell system were also evaluated. AH sampled was characterized as low quality, with low crude protein $(\mathrm{CP})$ concentration $(<2.5 \% \mathrm{DM})$, high neutral detergent fiber (NDF) (>78\% DM) and lignin (>8.7\% DM) contents, and $43.7 \%$ in vitro dry matter digestibility (IVDMD). Higher IVDMD and higher contents of CP, neutral detergent and acid detergent insoluble proteins, ash and phosphorus and smaller contents of fibers, total carbohydrates (TC) and magnesium were observed in the EXT, when compared to AH. Higher IVDMD and higher contents of $\mathrm{CP}$, non-fibrous carbohydrates (NFC), phosphorus (P) and potassium (K) were observed in the GL component and higher TC and NDF contents were observed in the GS, DL and DS components. High values of crude protein A fraction were observed in the GL and GS components, while low values were observed in the DL and DS components. High values of crude protein C fraction were also verified in the GS, DL and DS components. The potentially digestible CP fractions, except for $\mathrm{B}_{1}$ fraction, and NFC contents, were correlated with the $\mathrm{CP}$ contents in the forage components. Concerning the carbohydrates, low values of $\mathrm{NFC}\left(\mathrm{A}+\mathrm{B}_{1}\right)$ and high values of $\mathrm{C}$ fraction were observed in the GS, DL and DS components.
\end{abstract}

Key Words: herbage quality, signalgrass, tropical pasture

\section{Introdução}

De forma geral, a produção animal em pastagens tropicais é freqüentemente abaixo da desejada durante a maior parte do ano. Segundo Thiago et al. (1997), a baixa qualidade nutritiva e disponibilidade irregular de forragem nessas pastagens são os fatores mais importantes que afetam a produção animal em condições extensivas.

Conforme Euclides et al. (1993), animais em pastagens tropicais podem atingir bons ganhos de peso somente durante pequeno período na estação de

${ }_{1}^{1}$ Parte da dissertação de Mestrado apresentada pelo primeiro autor junto ao Depto. de Zootecnia da Universidade Federal de Viçosa. 2Engenheiro-Agrônomo, MS. E.mail: edestefani1@hotmail.com.br

3 Professor Orientador DZO - UFV, bolsista do CNPq. E.mail: mpaulino@ufv.br

${ }^{4}$ Zootecnista, DS, pesquisador EPAMIG.

${ }^{5}$ Professor DZO - UFV, bolsista do CNPq. 
crescimento das gramíneas, quando a disponibilidade e a proporção de folhas verdes na pastagem e a qualidade da forragem são adequadas, o que ocorre, com mais freqüência, nos Cerrados, entre o final da primavera a meados do verão.

Durante a estação seca/fria, as pastagens tropicais normalmente apresentam baixa disponibilidade de forragem de boa qualidade, em razão da avançada idade fisiológica das plantas forrageiras e da baixa rebrotação, decorrente da inibição causada pela presença de grande quantidade de perfilhos maduros, baixa umidade no solo, das temperaturas mais baixas e dos dias mais curtos. Assim, a sazonalidade da produção forrageira conduz freqüentemente à sazonalidade da produção animal, se a criação é conduzida em regime extensivo.

Para garantir determinado suprimento de pasto na época da baixa produção forrageira, os pecuaristas tradicionalmente vedam algumas pastagens no período chuvoso ou a partir do final das chuvas, acumulando forragem para utilização na seca. $\mathrm{O}$ diferimento da pastagem, desde que essa não esteja degradada, tem permitido aumentar a lotação animal e garantido a sobrevivência dos animais durante o período de seca.

No entanto, as gramíneas $\mathrm{C}_{4}$, que constituem os pastos tropicais, exibem alterações em suas características morfológicas e químicas, associadas ao desenvolvimento, à maturidade fisiológica e senescência natural da planta forrageira, que alteram a qualidade $\mathrm{e}$ a disponibilidade de forragem e a estrutura do relvado, influenciando o consumo e o desempenho dos animais (Euclides et al., 1990; Blaser, 1994; Gomide, 1997).

Euclides et al. (1990) e Leite \& Euclides (1994) mencionaram que, no início do estádio vegetativo, o teor de proteína bruta $(\mathrm{PB})$ e a digestibilidade in vitro da matéria orgânica dos pastos tropicais são geralmente altos. À medida que as plantas amadurecem, ocorrem espessamento e lignificação da parede e redução do conteúdo celular; a concentração dos componentes potencialmente digestíveis decresce e a de fibra aumenta. Segundo Minson (1990), muitas vezes, o teor de nitrogênio (N) no pasto disponível é inferior a $1 \%$ da matéria seca (MS), valor considerado limite mínimo para adequada atividade dos microrganismos ruminais.

Duble et al. (1971) verificaram que os teores de fibra em detergente neutro (FDN) de gramíneas tropicais variaram de 45 a $82 \%$ da MS; as amostras com teores mais baixos de FDN apresentaram maiores valores de digestibilidade in vitro da FDN (DIVFDN), até $82 \%$ e aquelas com teores mais altos de FDN, valores mais baixos de DIVFDN, em torno de $36 \%$. Os teores de FDN e a DIVFDN foram influenciados principalmente pela maturidade do perfilho e menos pela espécie forrageira.

Duble et al. (1971) e Guerrero et al. (1984) correlacionaram desempenho de animais em pastejo com oferta e qualidade da forragem disponível. Quando a digestibilidade in vitro da MS (DIVMS) da forragem decresceu, maior oferta de forragem foi necessária para atingir o ponto de máximo ganho de peso ou para manter o peso dos animais. Dentro dos limites desses estudos, quanto maior a DIVMS, mais elevado foi o ganho máximo de peso e menor disponibilidade de forragem foi necessária para atingir esse ponto.

Segundo Blaser (1994), a produção animal em pastagens tropicais é severamente restringida, devido ao rápido amadurecimento das plantas forrageiras e à conseqüente redução da disponibilidade e proporção de folhas verdes no relvado, ao aumento do teor de fibras e à redução do teor de $\mathrm{PB}$ e da digestibilidade da forragem disponível.

Conforme Corsi \& Nascimento Jr. (1986), os bovinos só atingem produções elevadas quando consomem quantidades adequadas de alimentos de alta qualidade; para que isso ocorra em regime de pastejo, há necessidade de grande disponibilidade e proporção de folhas verdes na pastagem.

Stobbs (1973) verificou que, durante a fase de crescimento de Setaria anceps e Chloris gayana, a porcentagem de folha diminuiu de 82 para $44 \%$ da disponibilidade de matéria seca total (DTMS) com o desenvolvimento dos perfilhos. $\mathrm{O}$ teor de $\mathrm{N}$ na forragem decresceu com a maturidade das plantas e das camadas superiores para as inferiores do relvado. A fração folha apresentou maior concentração de $\mathrm{N}$ que a fração caule. A DIVMS decresceu com a maturidade da forragem e das camadas superiores para as basais, com exceção da camada mais alta, que apresentou DIVMS menor que camadas inferiores, provavelmente devido à presença de inflorescências a partir da quarta semana de rebrotação dos pastos.

Por isso, de acordo com Euclides et al. (1990), Noller et al. (1997) e Reis et al. (1997), o diferimento de pastagens tropicais, para utilização na seca, tem proporcionado abundante suprimento de forragem de baixo valor nutritivo, suficiente apenas para a manutenção da vida do animal, que pode perder peso, devido ao baixo consumo de matéria seca digestível (CMSD). 
Assim, apesar do grande aumento do estoque de forragem com o diferimento das pastagens, observase, consistentemente, declínio do consumo de matéria seca (CMS) e da digestibilidade do pasto, em função do avanço da maturidade das plantas forrageiras. Em determinadas situações, pode ser verificado, associados ao declínio do CMS e da qualidade do pasto ingerido, aumento do tempo de pastejo e do gasto de energia pelo animal, em resposta também às alterações na estrutura do relvado, ou seja, em decorrência de redução da densidade de folhas verdes na forragem disponível e do aumento do grau de dificuldade para o animal selecionar os componentes do relvado de melhor qualidade.

A qualidade do pasto assume grande importância, porque a deficiência ou o baixo consumo de qualquer nutriente essencial restringe a produção animal (Blaser, 1994). De acordo com Noller et al. (1997), espera-se que os animais em pastejo consigam extrair energia, proteína e outros nutrientes da forragem para suprir suas necessidades alimentares e, se essas necessidades não forem atendidas pelo pasto e/ou por alimentos suplementares, o animal usará sua reserva corporal e/ou reduzirá sua produção.

O presente trabalho foi conduzido com os objetivos de estudar as características químico-bromatológicas da forragem disponível e dos componentes verdes e secos, presentes em pastagem de Brachiaria decumbens Stapf, após período de diferimento e sob pastejo contínuo durante a época seca, e também de verificar a existência de correlações entre características qualitativas do relvado e ganho de peso dos animais em pastejo.

\section{Material e Métodos}

Esse trabalho foi conduzido na Fazenda Experimental de Felixlândia (MG), pertencente à Empresa de Pesquisa Agropecuária de Minas Gerais (EPAMIG), no período de julho a outubro de 1997. Utilizou-se uma área cultivada com Brachiaria decumbens Stapf, subdividida em cinco piquetes de 8,9 ha cada. Em virtude da irregularidade das precipitações pluviométricas nessa região dos Cerrados, a pastagem foi vedada logo no início das chuvas, em dezembro de 1996, após passar por uma limpeza em novembro, seguindo os mesmos procedimentos tradicionalmente realizados pelos produtores locais. Os piquetes de Brachiaria decumbens foram utilizados em pastejo contínuo durante a seca, de julho a outu- bro, por 40 tourinhos $\mathrm{F}_{1}$ Limousin-Nelore, sendo oito animais por piquete, em ensaio com suplementos (Santos, 2000).

$\mathrm{O}$ experimento foi dividido em quatro períodos de 28 dias, com duração total de 112 dias e iniciou-se em 8 de junho de 1997. Foram efetuadas amostragens das pastagens por meio de dois métodos: pelo primeiro, amostras de Brachiaria decumbens foram colhidas com a ajuda de um quadrado de ferro com área de $1 \mathrm{~m}^{2}$ (disponibilidade total) nas datas: 8 de julho, 7 de agosto, 9 e 30 de setembro e 29 de outubro; pelo segundo, com o auxílio de animais fistulados no esôfago, colheram-se extrusas esofágicas (extrusa) nas datas: 7 de agosto, 9 e 30 de setembro e 29 de outubro.

Pelo método do quadrado, 10 amostras simples foram colhidas por piquete e por data de amostragem. O corte foi feito rente ao solo, de acordo com McMeniman (1997), colhendo-se toda a forragem na área do quadrado. As amostras foram pesadas e, dessas, retiraram-se subamostras para formar amostras compostas e em duplicatas, por piquete e data. De cada par de amostras compostas de forragem, uma foi acondicionada em saco plástico, identificada, congelada e, posteriormente, analisada para determinação das características químico-bromatológicas por data de amostragem; a outra foi utilizada para a separação dos componentes folha verde (FV), caule verde (CV), folha seca (FS) e caule seco (CS), por piquete e data. Bainhas foliares firmemente aderidas ao caule e inflorescências foram incluídas como caule. Em seguida, das amostras pré-secas e moídas de cada componente da forragem, formaram-se amostras compostas por data de amostragem, que foram analisadas para determinação das características químico-bromatológicas.

As extrusas foram colhidas de acordo com as recomendações de McMeniman (1997), utilizando-se outros cinco tourinhos $\mathrm{F}_{1}$ Limousin-Nelore, extras, fistulados no esôfago e rúmen, que no início dos trabalhos tinham de 17 a 18 meses de idade, e peso vivo médio durante o experimento de $260 \mathrm{~kg}$. Não foi possível colher extrusas na primeira amostragem, em 08 de julho. Amostras compostas de extrusa, por data de amostragem, foram analisadas para determinação das características químico-bromatológicas.

As análises de MS, PB, extrato etéreo (EE), cinzas (CZ), lignina (LIG) e minerais por via úmida, cálcio $(\mathrm{Ca})$, fósforo $(\mathrm{P})$, potássio $(\mathrm{K})$ e magnésio $(\mathrm{Mg})$ foram realizadas segundo Silva (1990) e as análises de FDN e fibra em detergente ácido (FDA), 
segundo Van Soest et al. (1991). As DIVMS das amostras de forragem foram obtidas conforme metodologia proposta por Tilley \& Terry (1963) e adaptada por Silva (1990).

A PB das amostras foi fracionada segundo Cornell Net Carbohydrate and Protein System (CNCPS) (Krishnamoorthy et al., 1982; e Licitra et al., 1996). A fração A da proteína (compostos nitrogenados não protéicos - CNNP, rapidamente degradados no rúmen: amônia, peptídios e aminoácidos) foi obtida por solubilização dessa fração em solução de ácido tricloroacético (TCA) a $10 \%$. A fração $\mathrm{B}_{1}$ (proteína verdadeira solúvel, rapidamente degradada no rúmen) foi obtida deduzindo-se a proteína solúvel em TCA $10 \%$ (fração A) da PB solúvel em tampão borato-fosfato. $\mathrm{A}$ fração $\mathrm{B}_{3}$ da proteína (proteínas associadas à parede celular; parcial e lentamente degradadas no rúmen) foi estimada por meio da fórmula $\mathrm{B}_{3}(\% \mathrm{~PB})=100 *[\mathrm{PIDN}(\% \mathrm{MS})-\mathrm{PIDA}$ $(\% \mathrm{MS})] / \mathrm{PB}(\% \mathrm{MS})$, sendo PIDN $[=6,25 *$ NIDN (\%MS)] a proteína insolúvel em detergente neutro, e PIDA $[=6,25 *$ NIDA $(\% \mathrm{MS})]$, a proteína insolúvel em detergente ácido. NIDN (nitrogênio insolúvel em detergente neutro) foi estimado como nitrogênio total no resíduo de FDN e NIDA (nitrogênio insolúvel em detergente ácido), no resíduo de FDA. A fração C (proteína insolúvel em detergente ácido; indisponível) foi determinada por meio da fórmula $\mathrm{C}(\% \mathrm{~PB})=100$ * PIDA (\%MS)/PB (\%MS) e a fração $\mathrm{B}_{2}$ (proteínas parcialmente degradadas no rúmen), por diferença.

Os carboidratos totais, obtidos de acordo com Sniffen et al. (1992) pela fórmula: CHT (\%MS $)=100$ $-[\mathrm{PB}(\% \mathrm{MS})+\mathrm{EE}(\% \mathrm{MS})+\mathrm{CZ}(\% \mathrm{MS})]$, foram fracionados em carboidratos não fibrosos (CNF), equivalente às frações $\mathrm{A}_{\text {e }} \mathrm{B}_{1}$ no sistema CNCPS); fração $\mathrm{B}_{2}$ (carboidratos estruturais, potencialmente digestíveis); e fração $\mathrm{C}$ (carboidratos indigestíveis no trato gastrintestinal dos ruminantes). Os CNF foram estimados, de acordo com Kabeya (2000), a partir da fórmula: $\mathrm{CNF}(\% \mathrm{MS})=[\mathrm{CHT}(\% \mathrm{MS})-\mathrm{FDNcp}$ $(\% \mathrm{MS})]$; ou CNF $(\% \mathrm{MS})=\{100-[\mathrm{PB}(\% \mathrm{MS})+\mathrm{EE}$ $(\% \mathrm{MS})+\mathrm{FDNcp}(\% \mathrm{MS})+\mathrm{CZ}(\% \mathrm{MS})]\}$, em que FDNcp é FDN desprovida de cinzas e proteína; e a fração CNF $(\% \mathrm{CHT})=\{100 *[\mathrm{CNF}(\% \mathrm{MS}) / \mathrm{CHT}$ (\%MS)]\}. A fração $\mathrm{C}$ de carboidratos nas amostras de forragem foi calculada de acordo com Gomes Jr. (2000), em que C $(\% \mathrm{CHT})=100 *\{\mathrm{FDNI}(\% \mathrm{MS}) *$ [FDNcp (\%MS)/FDN (\%MS)] \}/CHT (\%MS), em que FDNI foi obtida, segundo Cochran et al. (1986), do resíduo indigestível após 144 horas de incubação in vitro. $\mathrm{A}$ fração $\mathrm{B}_{2}$ de $\mathrm{CHT}$ foi calculada por diferença: $\mathrm{B}_{2}(\% \mathrm{CHT})=\{100 *[(\mathrm{FDNcp}(\% \mathrm{MS}) /$ CHT (\%MS)] - C (\%CHT)\}.

As concentrações médias dos componentes químico-bromatológicos nas amostras compostas de forragem (disponibilidade total e extrusa), colhidas nas datas de 7 de agosto, 9 e 30 de setembro e 29 de outubro, foram avaliadas em delineamento de blocos casualizados, onde os métodos de amostragem foram os tratamentos e as datas constituíram os blocos. As médias foram avaliadas por meio de análise de variância e comparadas utilizando-se o teste de Tukey e nível de significância de 5\% de probabilidade.

As concentrações dos nutrientes nos componentes do relvado foram avaliadas em delineamento de blocos casualizados, em que FV, CV, FS e CS constituíram os tratamentos e as épocas de amostragem, os blocos. As médias foram avaliadas por meio de análise de variância e comparadas utilizando-se o teste de Tukey e nível de significância de 5\% de probabilidade.

\section{Resultados e Discussão}

O diferimento da pastagem resultou em alta disponibilidade de forragem durante o período seco (julho ao final de outubro); a DMST foi, em média, $7.902 \mathrm{~kg} / \mathrm{ha}$ e a disponibilidade de matéria seca verde (DMSV), $3.265 \mathrm{~kg} / \mathrm{ha}$. Ao final de setembro, a DMST atingiu valor máximo $(8.418 \mathrm{~kg} / \mathrm{ha})$ e a DMSV valor mínimo (2.540 kg/ha) (Santos, 2000). As características químico-bromatólogicas da forragem durante o período seco estão apresentadas na Tabela 1 .

Durante todo o período amostrado, a forragem colhida pelo método da disponibilidade total apresentou teores de PB inferiores a 2,5\%, FDN superiores a $78 \%$ e lignina superiores a $8,7 \%$ na MS. Resultados semelhantes foram observados por Gomes Jr. (2000), que verificou teores médios de PB de $2,7 \%$ e de lignina de 9,0\% na MS de Brachiaria decumbens sob pastejo, na época seca. Esse autor observou teor mais elevado de FDN, 84,4\% na MS; teores similares de Ca, 0,32 ; e de P, $0,05 \%$ na MS; e DIVMS $(34,4 \%)$ e teor de $\mathrm{Mg}(0,12 \%$ na MS) inferiores aos verificados no presente trabalho. Conforme Noller et al. (1997), a digestibilidade de gramíneas tropicais cultivadas está em torno de 50 a $65 \%$ e decresce cerca de 0,1 a $0,2 \%$ por dia, com o aumento da idade fisiológica das plantas forrageiras.

A baixa qualidade nutricional da Brachiaria 
decumbens durante o período avaliado deveu-se certamente à avançada maturidade fisiológica da forrageira, decorrente do longo período de diferimento, à redução do extrato folhoso do relvado, em razão de sua utilização contínua pelos animais, e à baixa rebrotação do pasto, em virtude do inverno seco; e refletiu a baixa disponibilidade e proporção média de folhas verdes, $933 \mathrm{~kg} / \mathrm{ha}$, correspondente a apenas $11,8 \%$ da DTMS, da alta disponibilidade e participação de matéria seca morta, $58,6 \%$, e de matéria seca de caules (caule verde + caule seco), 60,2\% da DMST (Santos et al., 2004). Conforme Leite \& Euclides (1994), o pasto disponível, nessas condições, é uma combinação da rebrota e da forragem recusada.

Com exceção da primeira data de amostragem (8 de julho), quando não foi possível colher extrusas, as amostras de extrusa apresentaram maiores $(\mathrm{P}<0,05)$ DIVMS e teores de PB, CZ, PIDN, PIDA e P; e menores $(\mathrm{P}<0,05)$ teores de FDN, FDA, CHT e Mg, quando comparado com os teores na forragem total.

Tabela 1 - Teores médios (g/100 g de MS) e coeficientes de variação (CV\%) de proteína bruta (PB), proteína insolúvel em detergente neutro (PIDN), proteína insolúvel em detergente ácido (PIDA), cinzas (CZ), carboidratos totais $(\mathrm{CHT})$, carboidratos não fibrosos (CNF), fibra em detergente neutro (FDN), fibra em detergente ácido (FDA), lignina $(\mathrm{LIG})$, cálcio $(\mathrm{Ca})$, fósforo $(\mathrm{P})$, potássio $(\mathrm{K})$ e magnésio $(\mathrm{Mg})$ e digestibilidade in vitro da matéria seca (DIVMS) de forragem de Brachiaria decumbens, de acordo com o método de amostragem, disponibilidade total e extrusa, por data de amostragem

Table 1 - Average contents (g/100 g DM) and coefficients of variation (CV\%) of crude protein (CP), neutral detergent insoluble protein (NDIP), acid detergent insoluble protein (ADIP), ash, total carbohydrates (TC), non-fibrous carbohydrates (NFC), neutral detergent fiber (NDF), acid detergent fiber (ADF), lignin (LIG), calcium (Ca), phosphorus (P), potassium (K) and magnesium (Mg) and in vitro dry matter digestibility (IVDMD) in the forage of Brachiaria decumbens, according to the sampling method, total available forage and extrusa, for sampling date

\begin{tabular}{|c|c|c|c|c|c|c|c|c|c|c|c|}
\hline \multirow{2}{*}{$\begin{array}{l}\text { Item } \\
\text { Data } \\
\text { Date }\end{array}$} & \multicolumn{5}{|c|}{$\begin{array}{l}\text { Disponibilidade total } \\
\text { Total available forage }\end{array}$} & \multicolumn{6}{|c|}{$\begin{array}{l}\text { Extrusa } \\
\text { Extrusa }\end{array}$} \\
\hline & $\begin{array}{l}8 / \text { jul } \\
\text { Jul/8 }\end{array}$ & $\begin{array}{l}\text { 7/ago } \\
\text { Ago/7 }\end{array}$ & $\begin{array}{l}\text { 9/set } \\
\text { Sep/9 }\end{array}$ & $\begin{array}{l}\text { 30/set } \\
\text { Sep/30 }\end{array}$ & $\begin{array}{l}\text { 29/out } \\
\text { Oct } / 29\end{array}$ & $\begin{array}{l}\text { Média }^{1} \\
\text { Mean }\end{array}$ & $\begin{array}{l}\text { 7/ago } \\
\text { Ago/7 }\end{array}$ & $\begin{array}{l}9 / \mathrm{set} \\
\text { Sep/9 }\end{array}$ & $\begin{array}{l}30 / \text { set } \\
\text { Sep } / 30\end{array}$ & $\begin{array}{l}\text { 29/out } \\
\text { Oct/29 }\end{array}$ & $\begin{array}{r}\text { Média } \\
\text { Mean }\end{array}$ \\
\hline $\begin{array}{l}\mathrm{PB} \\
C P\end{array}$ & 2,45 & 2,16 & 2,08 & 2,35 & 2,14 & $2,19^{\mathrm{b}}$ & 7,18 & 3,81 & 5,53 & 8,87 & $6,35^{\mathrm{a}}$ \\
\hline $\begin{array}{l}\text { PIDN } \\
N D I P\end{array}$ & 1,18 & 0,81 & 0,71 & 0,97 & 0,97 & $0,87^{\mathrm{b}}$ & 3,68 & 1,75 & 3,16 & 2,98 & $2,89^{\mathrm{a}}$ \\
\hline $\begin{array}{l}\text { PIDA } \\
A D I P\end{array}$ & 0,48 & 0,54 & 0,53 & 0,62 & 0,55 & $0,56^{\mathrm{b}}$ & 1,15 & 0,90 & 1,16 & 0,98 & $1,05^{\mathrm{a}}$ \\
\hline $\begin{array}{l}\mathrm{CZ} \\
A s h\end{array}$ & 6,11 & 5,97 & 5,87 & 5,78 & 5,43 & $5,76^{\mathrm{b}}$ & 9,78 & 11,18 & 12,61 & 7,36 & $10,23^{\mathrm{a}}$ \\
\hline $\begin{array}{l}\text { CHT } \\
T C\end{array}$ & 90,9 & 91,29 & 91,48 & 91,23 & 91,88 & $91,47^{\mathrm{a}}$ & 80,81 & 83,77 & 81,22 & 82,17 & $81,99^{b}$ \\
\hline $\begin{array}{l}\mathrm{CNF} \\
N F C\end{array}$ & 12,1 & 14,34 & 12,50 & 11,91 & 10,99 & $12,43^{\mathrm{a}}$ & 13,22 & 13,53 & 12,83 & 14,25 & $13,46^{\mathrm{a}}$ \\
\hline $\begin{array}{l}\text { FDN } \\
N D F\end{array}$ & 80,9 & 78,63 & 80,66 & 81,38 & 82,92 & $80,90^{\mathrm{a}}$ & 73,37 & 74,70 & 74,78 & 71,97 & $73,70^{\mathrm{b}}$ \\
\hline $\begin{array}{l}\text { FDA } \\
A D F\end{array}$ & 45,2 & 44,22 & 47,26 & 46,98 & 51,53 & $47,50^{\mathrm{a}}$ & 37,18 & 40,09 & 42,90 & 37,93 & $39,52^{b}$ \\
\hline LIG & 10,8 & 10,98 & 12,61 & 11,25 & 12,76 & $11,90^{\mathrm{a}}$ & 13,18 & 11,98 & 12,58 & 11,58 & $9,24^{\mathrm{a}}$ \\
\hline $\mathrm{Ca}$ & 0,41 & 0,37 & 0,31 & 0,35 & 0,30 & $0,33^{\mathrm{a}}$ & 0,44 & 0,46 & 0,40 & 0,34 & $0,41^{\mathrm{a}}$ \\
\hline $\mathrm{P}$ & 0,07 & 0,07 & 0,06 & 0,06 & 0,06 & $0,06^{\mathrm{b}}$ & 0,37 & 0,25 & 0,32 & 0,22 & $0,29^{\mathrm{a}}$ \\
\hline K & 1,28 & 1,39 & 1,28 & 1,07 & 1,08 & $1,20^{\mathrm{a}}$ & 1,62 & 1,55 & 1,50 & 1,93 & $1,65^{\mathrm{a}}$ \\
\hline $\mathrm{Mg}$ & 0,20 & 0,21 & 0,17 & 0,16 & 0,15 & $0,17^{\mathrm{a}}$ & 0,13 & 0,15 & 0,12 & 0,13 & $0,13^{\mathrm{b}}$ \\
\hline $\begin{array}{l}\text { DIVMS } \\
I V D M D\end{array}$ & 45,5 & 46,12 & 43,38 & 42,22 & 40,11 & $42,96^{\mathrm{b}}$ & 58,33 & 69,51 & 68,81 & 69,08 & $66,43^{\mathrm{a}}$ \\
\hline
\end{tabular}

${ }^{1}$ Médias desconsiderando dados obtidos em 8/julho.

${ }^{1}$ Means not considering data obtained in July 8.

Médias seguidas por letras diferentes na mesma linha diferem $(P<0,05)$ pelo teste Tukey.

Means followed by different letter, within a row, differ $(P<.05)$ by Tukey test. 
Esses resultados refletiram o comportamento ingestivo dos animais, que, dentro de suas limitações, selecionam os componentes do relvado de melhor qualidade (Allden \& Whittaker, 1970; Stobbs, 1973; Hodgson et al., 1994).

Gomes Jr. (2000) observou, em extrusas obtidas em piquetes de capim-braquiária na época seca, teores de PB, 6,76; FDN, 74,96; Ca, 0,41; e Mg, 0,12\% na MS, similares aos encontrados neste estudo. No entanto, os teores de LIG, 7,49; P, 0,17\% na MS; e DIVMS, $46,2 \%$, diferiram dos resultados verificados no presente trabalho. Kabeya (2000), analisando amostras de capim-braquiária obtidas por pastejo simulado no final da seca, verificou teor de PB igual a 6,97 e de FDN, $71,1 \%$ na MS. Esses valores estão próximos aos verificados em extrusas no presente trabalho.

A forragem disponível em pastagens tropicais, principalmente quando o pasto é constituído por perfilhos maduros, normalmente não representa a forragem selecionada pelos animais (Allden \& Whittaker, 1970; Stobbs, 1973). Inúmeros estudos demonstraram que bovinos em pastejo selecionam forragem verde em detrimento da morta. Euclides et al. (1992) observaram que dietas selecionadas por animais em pastagens tropicais apresentavam, em média, $90 \%$ de matéria seca verde (MSV), enquanto as porcentagens de MSV disponíveis nas pastagens eram de $26 \%$ na de Brachiaria decumbens e de $23 \%$ na de Brachiaria humidicola.

Conforme Hodgson et al. (1994), a dieta colhida pelo animal na pastagem é a selecionada segundo a preferência, mas modificada pela disponibilidade e acessibilidade dos componentes preferidos e menos preferidos. Conseqüentemente, o nível potencial de ingestão, a digestibilidade da dieta e, principalmente, o desempenho dos animais são claramente influenciados pela maturidade da forragem disponível e pela distribuição de componentes de diferentes digestibilidades no relvado.

É necessário ressalvar também que o processo de amostragem da forragem por meio de extrusas pode conduzir a alterações nos teores de $\mathrm{PB}, \mathrm{P}$ e Na, em decorrência de contaminação com a saliva do animal, e perda de CNF se a saliva é drenada da amostra (Euclides et al., 1992; Vieira, 1998). Portanto, os teores desses nutrientes contidos nas amostras de extrusas podem não corresponder aos teores no pasto colhido pelos animais.

Uma vez que a disponibilidade, proporção, distribuição e qualidade de FV, CV, FS e CS no relvado influenciam o CMS e o desempenho dos animais em pastejo, a separação e a análise químico-bromatológica desses componentes do relvado podem, de certa forma, caracterizar melhor a forragem disponível (Tabela 2).

A fração FV apresentou maiores $(\mathrm{P}<0,05)$ teores de $\mathrm{PB}, \mathrm{CNF}$, PIDN, $\mathrm{P}$ e $\mathrm{K}$, maior $(\mathrm{P}<0,05)$ DIVMS e menores $(\mathrm{P}<0,05)$ teores de FDN, FDA, FDNcp, CHT e LIG que os outros componentes do pasto. Somente FV apresentou teor de N próximo a 1\% da MS. Assim, o consumo de maiores proporções dos outros componentes, que não FV, poderia resultar em balanço negativo de $\mathrm{N}$ e redução do CMS pelos animais.

Os componentes FV e FS apresentaram maiores $(\mathrm{P}<0,05)$ valores de DIVMS e teores de CZ, EE, Ca e $\mathrm{Mg}$ e menores teores de FDN, FDA, LIG e CHT, em relação aos componentes CV e CS. O teor de PIDA foi maior $(\mathrm{P}<0,05)$ em FS que em $\mathrm{FV}$ e em CS que em $\mathrm{CV}$. O componente $\mathrm{CV}$ apresentou maior $(\mathrm{P}<0,05)$ teor de $\mathrm{K}$, mas não diferiu $(\mathrm{P}>0,05) \mathrm{em}$ relação aos teores de PB, PIDN e P, quando comparado aos componentes da fração morta (FS e CS), e conteve menores $(\mathrm{P}<0,05)$ teores de FDN, FDA, FDNcp, PIDA e Ca e maiores de CNF e K, quando comparado ao componente CS.

Ao comparar FV com FS e CV com CS, em relação às concentrações dos componentes químicos, verifica-se que o fenômeno da translocação de substâncias celulares pode fazer com que a concentração daquelas que são pouco, ou não são, translocadas, aumente nos tecidos vegetais senescentes, como verificado em relação à FDN, FDA, PIDA e ao Ca.

A data de amostragem da pastagem não influenciou $(\mathrm{P}>0,05)$ as concentrações de $\mathrm{PB}, \mathrm{CNF}, \mathrm{FDN}$, FDNcp, CHT, PIDN, P e K, na MS dos componentes FV, CV, FS e CS. Todavia, o teor de FDA foi menor $(\mathrm{P}<0,05)$ em 8 de julho, aumentou gradativamente durante a seca e foi maior $(\mathrm{P}<0,05)$ em 29 de outubro; o teor de CZ foi menor $(\mathrm{P}<0,05)$ em 09 e 30 de setembro, auge da seca; o teor de LIG foi menor $(\mathrm{P}<0,05)$ em 07 de agosto, época de maior DMSV; o teor de $\mathrm{EE}$ foi maior $(\mathrm{P}<0,05)$ em 29 de outubro, com a rebrotação dos pastos; os teores de $\mathrm{Ca}$ e $\mathrm{Mg}$ foram maiores $(\mathrm{P}<0,05)$ em 8 de julho e 07 de agosto, primeira metade da seca; e a DIVMS foi maior $(\mathrm{P}<0,05)$ em 8 de julho e 07 de agosto, embora não diferisse $(\mathrm{P}>0,05)$ do valor exibido em 30 de setembro.

Na Tabela 3, estão apresentadas as frações de proteína e carboidratos contidos nos componentes do relvado, expressas como porcentagem de PB e CHT, 
respectivamente. Essas frações são apresentadas no texto, também, em termos de concentração na MS das amostras analisadas. O fracionamento de proteínas e carboidratos dietéticos, nas frações rapidamente e lentamente disponíveis e na fração indisponível, permite melhor estimação da disponibilidade potencial desses nutrientes, assim como a verificação de qualidades e limitações dos alimentos para a nutrição dos animais.
A data de amostragem da pastagem não influenciou $(\mathrm{P}>0,05)$ as concentrações das frações da PB e dos CHT na MS dos componentes FV, CV, FS e CS. Os valores da fração A da proteína (CNNP) corresponderam aproximadamente à terça parte da $\mathrm{PB}$ nos componentes verdes (FV e CV) e a $16 \%$ da PB nos componentes secos (FS e CS). As concentrações dessa fração da PB nos componentes FV, CV, FS e CS foram,

Tabela 2 - Teores médios ( $\mathrm{g} / 100 \mathrm{~g}$ de MS) de proteína bruta (PB), proteína insolúvel em detergente neutro (PIDN), proteína insolúvel em detergente ácido (PIDA), extrato etéreo (EE), cinzas (CZ), carboidratos totais $(\mathrm{CHT})$, carboidratos não fibrosos (CNF), fibra em detergente neutro (FDN), fibra em detergente neutro livre de cinzas e proteína (FDNcp), fibra em detergente ácido (FDA), lignina (LIG), cálcio (Ca), fósforo $(\mathrm{P})$, potássio $(\mathrm{K})$ e magnésio $(\mathrm{Mg})$ e digestibilidade in vitro da matéria seca (DIVMS) nos componentes folha verde (FV), caule verde (CV), folha seca (FS) e caule seco (CS) de Brachiaria decumbens, durante a época seca

Table 2 - Average contents ( $g / 100 \mathrm{~g} D M$ ) of crude protein $(C P)$, neutral detergent insoluble protein $(N D I P)$, acid detergent insoluble protein (ADIP), ether extract (EE), ash, total carbohydrates (TC), non-fibrous carbohydrates (NFC), neutral detergent fiber (NDF), neutral detergent fiber free ash and protein $\left(N D F_{a p}\right)$, acid detergent fiber (ADF), lignin (LIG), calcium (Ca), phosphorus $(P)$, potassium $(K)$ e magnesium $(M g)$ and in vitro dry matter digestibility (IVDMD) in the green leaf (GL), green stem (GS), dry leaf (DL) and dry stem (DS) components of the Brachiaria decumbens forage, during the dry season

\begin{tabular}{|c|c|c|c|c|}
\hline Item & $\begin{array}{l}\mathrm{FV} \\
G L\end{array}$ & $\begin{array}{l}\mathrm{CV} \\
G S\end{array}$ & $\begin{array}{l}\text { FS } \\
D L\end{array}$ & $\begin{array}{l}\text { CS } \\
D S\end{array}$ \\
\hline $\begin{array}{l}\mathrm{PB} \\
C B\end{array}$ & $6,04^{\mathrm{a}}$ & $1,80^{\mathrm{b}}$ & $2,32^{\mathrm{b}}$ & $1,19^{\mathrm{b}}$ \\
\hline $\begin{array}{l}\text { PIDN } \\
N D I P\end{array}$ & $2,25^{\mathrm{a}}$ & $0,62^{\mathrm{b}}$ & $1,12^{\mathrm{b}}$ & $0,59^{\mathrm{b}}$ \\
\hline $\begin{array}{l}\text { PIDA } \\
A D I P\end{array}$ & $0,44^{\mathrm{bc}}$ & $0,37^{\mathrm{c}}$ & $0,55^{\mathrm{a}}$ & $0,52^{\mathrm{ab}}$ \\
\hline $\begin{array}{l}\mathrm{EE} \\
\mathrm{CZ} \\
\text { Ash }\end{array}$ & $\begin{array}{l}1,38^{\mathrm{a}} \\
8,09^{\mathrm{a}}\end{array}$ & $\begin{array}{l}0,46^{\mathrm{b}} \\
4,67^{\mathrm{b}}\end{array}$ & $\begin{array}{l}1,39^{\mathrm{a}} \\
8,09^{\mathrm{a}}\end{array}$ & $\begin{array}{l}0,46^{\mathrm{b}} \\
4,31^{\mathrm{b}}\end{array}$ \\
\hline $\begin{array}{l}\text { CHT } \\
T C\end{array}$ & $84,48^{c}$ & $93,07^{\mathrm{a}}$ & $88,21^{b}$ & $94,04^{\mathrm{a}}$ \\
\hline $\begin{array}{l}\mathrm{CNF} \\
N F C\end{array}$ & $20,30^{\mathrm{a}}$ & $12,52^{b}$ & $13,37^{b}$ & $7,65^{\mathrm{c}}$ \\
\hline $\begin{array}{l}\text { FDN } \\
N D F\end{array}$ & $67,39^{\mathrm{d}}$ & $81,54^{b}$ & $77,66^{\mathrm{c}}$ & $87,78^{\mathrm{a}}$ \\
\hline $\begin{array}{l}\text { FDNcp } \\
\text { NDFap }\end{array}$ & $64,18^{\mathrm{d}}$ & $80,55^{b}$ & $74,84^{\mathrm{c}}$ & $86,39^{\mathrm{a}}$ \\
\hline $\begin{array}{l}\text { FDA } \\
A D F\end{array}$ & $29,84^{\mathrm{d}}$ & $48,34^{\mathrm{b}}$ & $39,10^{c}$ & $54,76^{\mathrm{a}}$ \\
\hline $\begin{array}{l}\mathrm{LIG} \\
\mathrm{Ca}\end{array}$ & $\begin{array}{l}3,06^{\mathrm{c}} \\
0,46^{\mathrm{b}}\end{array}$ & $\begin{array}{l}9,83^{\mathrm{a}} \\
0,12^{\mathrm{d}}\end{array}$ & $\begin{array}{l}4,97^{\mathrm{b}} \\
0,69^{\mathrm{a}}\end{array}$ & $\begin{array}{l}9,55^{\mathrm{a}} \\
0,24^{\mathrm{c}}\end{array}$ \\
\hline $\mathrm{P}$ & $0,14^{\mathrm{a}}$ & $0,08^{\mathrm{b}}$ & $0,07^{\mathrm{b}}$ & $0,04^{\mathrm{b}}$ \\
\hline K & $3,00^{\mathrm{a}}$ & $\begin{array}{l}1,50^{\mathrm{b}} \\
0,11^{\mathrm{b}}\end{array}$ & $0,64^{\mathrm{c}}$ & $\begin{array}{l}0,65^{\mathrm{c}} \\
0,14^{\mathrm{b}}\end{array}$ \\
\hline $\begin{array}{l}\mathrm{Mg} \\
\text { DIVMS } \\
\end{array}$ & $\begin{array}{r}0,25^{\mathrm{a}} \\
62,14^{\mathrm{a}}\end{array}$ & $\begin{array}{r}0,11^{\mathrm{b}} \\
36,67^{\mathrm{c}}\end{array}$ & $\begin{array}{r}0,24^{\mathrm{a}} \\
50,31^{\mathrm{b}}\end{array}$ & $\begin{array}{r}0,14^{\mathrm{b}} \\
35,88^{\mathrm{c}}\end{array}$ \\
\hline
\end{tabular}

Médias seguidas por letras diferentes na mesma linha diferem $(P<0,05)$ pelo teste Tukey. Means followed by different letter, within a row, differ $(P<.05)$ by Tukey test. 
respectivamente, 19,8; 6,4; 3,6; e 1,9 g por kg de MS.

Os valores da fração $\mathrm{B}_{1}$ da proteína nos componentes do pasto apresentaram-se muito baixos, como é verificado freqüentemente em amostras de forragem, e foram: 1,$2 ; 0,9 ; 1,7$ e $1,4 \mathrm{~g} / \mathrm{kg}$ na MS, respectivamente, em FV, CV, FS e CS. Os teores da fração $\mathrm{B}_{2}$ da proteína foram: 17,$3 ; 4,5 ; 6,6 ; \mathrm{e} 2,6 \mathrm{~g} / \mathrm{kg}$ na MS; os teores da fração $\mathrm{B}_{3}$ (proteína potencialmente digestível da parede celular): 17,$6 ; 2,3 ; 5,7 ;$ e $0,8 \mathrm{~g} / \mathrm{kg}$ na MS, e as concentrações de PIDA, 4,4; 3,8; 5,5 e $5,2 \mathrm{~g} / \mathrm{kg}$ na MS dos componentes FV, CV, FS e CS, respectivamente. Embora os teores de PIDA na MS fossem relativamente baixos, no componente CS, os valores dessa fração corresponderam, em média, a $43,7 \%$ da PB, o que significa que, além do baixo teor de PB nesse componente, ela era, em grande parte, indisponível. Pode-se concluir que a disponibilidade de PB para o animal mantido nessas condições depende essencialmente do consumo de folhas verdes, embora o teor protéico desse componente do relvado tenha sido baixo em função da maturidade dos perfilhos.

Gomes Jr. (2000) observou em amostras de capimbraquiária, obtidas pelo método de pastejo simulado, valores da fração A da proteína variando de 9,0 a $38,5 \mathrm{~g}$ por kg de MS; fração protéica $\mathrm{B}_{1}$, de 1,8 a $4,2 \mathrm{~g} / \mathrm{kg}$ na MS; fração protéica $\mathrm{B}_{2}$, de 13,6 a $27,8 \mathrm{~g} / \mathrm{kg}$ na MS; fração protéica $\mathrm{B}_{3}$, de 4,9 a $14,9 \mathrm{~g} / \mathrm{kg}$ na MS; e PIDA, de 3,5 a 8,7 g/kg na MS. Todas as frações protéicas, com exceção de PIDA, tiveram suas concentrações na MS reduzidas de dezembro (época das águas) para outubro (seca) do ano seguinte.

Nas condições do presente trabalho, as concentrações das frações da proteína, com exceção da fração $B_{1}$ e PIDA, correlacionaram-se com o teor de $\mathrm{PB}$ na MS dos componentes da planta forrageira. $\mathrm{Na}$ Tabela 4, estão apresentadas as equações de regressão ajustadas para as concentrações das frações protéicas, em função da concentração de PB nos componentes do pasto.

Tabela 3 - Teores de proteína bruta $(P B)$ e de carboidratos totais $(C H T)$ e valores das frações protéicas $\left(A, B_{1}, B_{2}, B_{3}\right.$ e PIDA) e de carboidratos totais (CNF, $B_{2}$ e $\left.C\right)$, contidos nos componentes folha verde (FV), caule verde (CV), folha seca (FS) e caule seco (CS) de Brachiaria decumbens, na época seca

Table 3 - Contents of crude protein (CP) and of total carbohydrates (TC), and values of crude protein fractions $\left(A, B_{1}, B_{2}, B_{3}\right.$ and $\left.A D I P\right)$ and total carbohydrates fractions (NFC, $B_{2}$ and $C$ ) in the green leaf $(G L)$, green stem (GS), dry leaf $(D L)$ and dry stem (DS) components of the Brachiaria decumbens forage, during the dry season

\begin{tabular}{lcccc}
\hline Item & $\mathrm{FV}$ & $\mathrm{CV}$ & $\mathrm{FS}$ & $\mathrm{CS}$ \\
& $G L$ & $G S$ & $D L$ & $D S$ \\
\hline $\mathrm{PB}(\% \mathrm{MS})$ & $6,04^{\mathrm{a}}$ & $1,80^{\mathrm{b}}$ & $2,32^{\mathrm{b}}$ & $1,19^{\mathrm{b}}$ \\
$C P(\% D M)$ & & & & \\
$\mathrm{CHT}(\% \mathrm{MS})$ & $84,48^{\mathrm{c}}$ & $93,07^{\mathrm{a}}$ & $88,21^{\mathrm{b}}$ & $94,04^{\mathrm{a}}$ \\
$T C(\% D M)$ & & & \\
\hline
\end{tabular}

\begin{tabular}{|c|c|c|c|c|}
\hline \multicolumn{5}{|c|}{$\begin{array}{c}\text { Frações protéicas }(\% \mathrm{~PB}) \\
\text { Protein fractions }(\% C P)\end{array}$} \\
\hline A & $32,92^{\mathrm{a}}$ & $35,59^{\mathrm{a}}$ & $15,65^{\mathrm{b}}$ & $16,07^{b}$ \\
\hline $\mathrm{B}_{1}$ & $1,96^{\mathrm{a}}$ & $5,05^{\mathrm{a}}$ & $7,35^{\mathrm{a}}$ & $11,55^{\mathrm{a}}$ \\
\hline $\mathrm{B}_{2}$ & $28,60^{\mathrm{a}}$ & $25,14^{\mathrm{ab}}$ & $28,51^{\mathrm{ab}}$ & $22,26^{\mathrm{b}}$ \\
\hline $\mathrm{B}_{3}$ & $29,23^{\mathrm{a}}$ & $12,97^{\mathrm{b}}$ & $24,82^{\mathrm{a}}$ & $6,38^{\mathrm{b}}$ \\
\hline $\operatorname{PIDA}(\mathrm{C})$ & $7,28^{\mathrm{c}}$ & $21,24^{\mathrm{b}}$ & $23,67^{b}$ & $43,75^{\mathrm{a}}$ \\
\hline$A D I P(C)$ & & & & \\
\hline \multicolumn{3}{|c|}{ Total carbohydrates fractions (\%TC) } & & \\
\hline$\overline{\mathrm{CNF}}$ & & & & \\
\hline$N F C$ & $24,03^{\mathrm{a}}$ & $13,43^{b}$ & $15,15^{\mathrm{b}}$ & $8,13^{\mathrm{c}}$ \\
\hline $\mathrm{B}_{2}$ & $51,12^{\mathrm{a}}$ & $34,49^{b}$ & $52,30^{\mathrm{a}}$ & $45,68^{\mathrm{a}}$ \\
\hline $\mathrm{C}$ & $24,85^{\mathrm{b}}$ & $52,08^{\mathrm{a}}$ & $32,56^{\mathrm{b}}$ & $46,19^{\mathrm{a}}$ \\
\hline
\end{tabular}

Médias seguidas por letras diferentes na mesma linha diferem $(\mathrm{P}<0,05)$ pelo teste Tukey.

Means followed by different letter, within a row, differ $(P<.05)$ by Tukey test. 
O teor de PB das amostras é essencialmente a somatória das contribuições das diversas frações da proteína. No entanto, espera-se que algumas dessas frações estejam mais correlacionadas com o teor de PB da amostra e que outras frações possam não se correlacionar, em parte, porque os componentes FV, CV, FS e CS são morfológica e quimicamente diferentes. Por exemplo, não era esperado que a fração A da PB apresentasse tal correlação com o teor protéico dos componentes do relvado, porque os compostos nitrogenados não protéicos, como aminoácidos, nitratos, nitritos e amônia, principais constituintes dessa fração protéica, são tóxicos quando em altas concentrações. Isso implica que há limite máximo para a concentração intracelular dessa fração protéica. Mesmo assim, Ribeiro et al. (2001) observaram altos teores dessa fração da PB em feno de capim-tifton 85 (Cynodon spp.) com idades entre 28 e 56 dias de rebrota, que variaram de 36,4 a $44,7 \mathrm{~g} / \mathrm{kg}$ na MS.

Os teores de PIDA também não se correlacionaram com os teores de PB da amostra. Resultados mais precisos talvez possam ser obtidos procedendo-se essa correlação para amostras compostas somente de folhas ou de caules; ou mais especificamente para determinado componente, ou ainda para a planta inteira, em relação ao estádio fisiológico. No entanto, Vitori (1998) verificou que os teores de PB e PIDA na MS da planta inteira de Canarana, capim-angola, Hermathria e Tifton correlacionaram-se linear e negativamente com a idade de corte (14 a 56 dias), indicando relação entre seus teores, fato não observado por Ribeiro et al.(2001), mas que pode estar relacionado ao alongamento dos caules e espessamento da parede celular.

Os CNF $\left(A+B_{1}\right)$ corresponderam a 203, 125, 134 e $76 \mathrm{~g} / \mathrm{kg}$ na MS de FV, CV, FS e CS, respectivamente. Em relação a essa fração, percebe-se que os componentes CV e FS da Brachiaria decumbens, nas condições desse trabalho, apresentaram valor nutricional similar para os ruminantes. Foi verificada também correlação significativa $(\mathrm{P}<0,05)$ entre as concentrações de CNF e de PB nas amostras dos componentes do relvado, de acordo com a equação ajustada: $\hat{\mathrm{Y}}_{[\mathrm{CNF}]}=2,2678 * \mathrm{X}_{[\mathrm{PB}]}+70,2504$, sendo $\mathrm{r}^{2}=90,6$, em que $\hat{\mathrm{Y}}_{[\mathrm{CNF}]}=$ concentração da fração $\mathrm{CNF}$, em $\mathrm{g} / \mathrm{kg}$ na MS; $\mathrm{X}_{[\mathrm{PB}]}=$ concentração de $\mathrm{PB}$ nas amostras dos componentes FV, CV, FS e CS, em $\mathrm{g} / \mathrm{kg}$ na MS.

Os teores da fração de carboidratos $\mathrm{B}_{2}$, associada à parede celular vegetal, verificados nesse trabalho, foram: 432, 321, 461 e $430 \mathrm{~g} / \mathrm{kg}$ na MS dos componentes FV, CV, FS e CS, respectivamente. Essa fração constitui a principal fonte de energia para os ruminantes alimentados com volumosos. Todavia, a energia que essa fração pode disponibilizar para o animal é muito variável e depende de sua taxa de digestão e da taxa de passagem do alimento, como também da presença de proteína degradável, a taxas compatíveis, e/ou da reciclagem eficiente de $\mathrm{N}$ para o rúmen e de uma população microbiana celulolítica ativa.

Tabela 4 - Equações de regressão e coeficientes de determinação $\left(r^{2}\right)$ ajustados para as concentrações das frações da proteína $\left(A, B_{1}, B_{2}, B_{3} e\right.$ PIDA, em $\mathrm{g} / \mathrm{kg}$ na MS) em função da concentração de proteína ( $X$, em $\mathrm{g} / \mathrm{kg}$ na MS) nos componentes do pasto de Brachiaria decumbens Table 4 - Regression equations and coefficients of determination $\left(r^{2}\right)$ for the protein fractions contents $\left(A, B_{1}, B_{2}, B_{3}\right.$ and $A D I P, g / k g$ in $\left.D M\right)$ in relation to the crude protein contents $(X, g / k g$ in $D M)$ in the Brachiaria decumbens grass components

\begin{tabular}{ccc}
\hline $\begin{array}{c}\text { Concentração da fração protéica } \\
\text { Protein fractions contents }\end{array}$ & $\begin{array}{c}\text { Regressão } \\
\text { Regression }^{1}\end{array}$ & $\mathrm{r}^{2}$ \\
\hline $\mathrm{A}$ & $\hat{\mathrm{Y}}=-0,3514 * \mathrm{X}+2,1408$ & 94,3 \\
$\mathrm{~B}_{1}$ & n.s. & - \\
$\mathrm{B}_{2}$ & $\hat{\mathrm{Y}}=0,3017 * \mathrm{X}-0,7538$ & 99,8 \\
$\mathrm{~B}_{3}$ & $\hat{\mathrm{Y}}=0,3564 * \mathrm{X}-3,3592$ & 99,4 \\
$\mathrm{PIDA}$ & n.s. & - \\
ADIP & & \\
\hline
\end{tabular}

${ }^{1} \mathrm{~F}$ significativo a $5 \%$.

${ }^{1} \mathrm{~F}$ significant at $5 \%$. 
Gomes Jr. (2000) verificou em amostras de capim-braquiária, obtidas pelo método de pastejo simulado, valores da fração CNF variando de 143,26 a $186,34 \mathrm{~g} / \mathrm{kg}$ de MS; e fração $\mathrm{B}_{2}$ de carboidratos totais, de 416,08 a 474,73 g/kg na MS.

A fração de carboidratos C correspondeu a 210, 485,287 e $435 \mathrm{~g} / \mathrm{kg}$ na MS dos componentes FV, CV, FS e CS, respectivamente. Gomes Jr. (2000) verificou que, em amostras de forragem obtidas pelo método do pastejo simulado, os teores da fração $\mathrm{C}$ de carboidratos aumentaram do período das águas, em dezembro, de $169,8 \mathrm{~g} / \mathrm{kg}$ de MS, para valor máximo em outubro, de $285,6 \mathrm{~g} / \mathrm{kg}$ na MS, no final do período seco.

No presente trabalho, nota-se, adicionalmente, que FS apresentou 40,8\% menos carboidratos na fração $\mathrm{C}$ quando comparado a $\mathrm{CV}$. Portanto, em condições como a deste experimento, no qual a proporção e disponibilidade de FV na pastagem eram baixas e a de material morto, alta, o componente FS pode apresentar razoável potencial como alimento energético para o animal, desde que seja fornecida suplementação de proteína degradável no rúmen.

Apesar de o caule seco de algumas forrageiras, como, por exemplo, de Brachiaria ruziziensis, ser consumido com facilidade pelos animais em pastejo e apresentar razoável valor energético, o caule é uma estrutura de suporte e resistência da planta, o que justifica o alto teor da fração $\mathrm{C}$ de $\mathrm{CHT}$, que foi equivalente ao seu teor de FDA.

Comparando-se os teores das frações de carboidratos nos componentes CV e CS, verifica-se que a fração de carboidratos $\mathrm{C}$ em CV é maior que em CS, contrastando com o esperado, embora os teores de LIG nesses componentes do relvado fossem semelhantes. No entanto, pode ter ocorrido subestimação da fração $\mathrm{C}$ e, por diferença, superestimação da fração $\mathrm{B}_{2}$. Portanto, outras metodologias devem ser usadas em paralelo a essa para melhor comparação dos resultados.

\section{Conclusões}

$\mathrm{O}$ diferimento da pastagem de capim-braquiária resultou em grande produção de forragem de baixa qualidade, devido à baixa concentração de proteína, alta de fibra e à baixa digestibilidade in vitro da matéria seca.

A dieta selecionada pelos animais na pastagem apresentou maior digestibilidade e maiores teores de proteína bruta, proteína insolúvel em detergente neutro e ácido, cinzas e fósforo e menores teores de fibras, carboidratos totais e magnésio, quando comparada com os valores observados na forragem disponível.

O componente folha verde apresentou maior digestibilidade e maiores teores de proteína bruta, carboidratos não fibrosos, fósforo e potássio e menores teores de fibras e carboidratos totais, quando comparado aos outros componentes do pasto. Somente o componente folha verde conteve teores de $\mathrm{N}$ próximo a $1 \%$ da MS durante o período seco.

As concentrações das frações potencialmente digestíveis da proteína, com exceção da fração $\mathrm{B}_{1}$, correlacionaram-se com o teor protéico nos componentes folha verde, caule verde, folha seca e caule seco, da planta forrageira.

Durante a seca, o componente folha seca de Brachiaria decumbens apresentou razoável potencial como alimento energético para o animal, no entanto, o aumento do consumo dessa fração pode elevar a exigência pelo animal de proteína degradável no rúmen.

\section{Literatura Citada}

ALLDEN, W.G.; WHITTAKER, I.A. The determinants of herbage intake by grazing sheep: the interrelationship of factors influencing herbage intake and availability. Australian Journal Agriculture Research, v.21, n.5, p.755-766, 1970.

BLASER, R.E. Manejo do complexo pastagem-animal para avaliação de plantas e desenvolvimento de sistemas de produção de forragens. In: PEIXOTO, A.M. (Ed.). Pastagens: fundamentos da exploração racional. 2.ed. Piracicaba: Fundação de Estudos Agrários Luiz de Queiroz, 1994. p.279-335.

COCHRAN, R.C.; ADAMS, D.C.; WALLACE, J.D. et al. Predicting digestibility of different diets with internal markers: evaluation of four potential markers. Journal of Animal Science, v.63, n.5, p.1469-1475, 1986.

CORSI, M.; NASCIMENTO JR., D. Princípios de fisiologia e morfologia de plantas forrageiras aplicados no manejo das pastagens. In: PEIXOTO, A.M.; MOURA J.C.; FARIA, V.P. (Eds.). Pastagens: fundamentos da exploração racional. 1. ed. Piracicaba: Fundação de Estudos Agrários Luiz de Queiroz, 1986. p.11-37.

DUBLE, R.L.; LANCASTER, J.A.; HOLT, E.C. Forage characteristics limiting animal performance on warmseason perennial grasses. Agronomy Journal, v.63, n.3, p.795-798, 1971.

EUCLIDES, V.P.B.; VALLE, C.B.; SILVA, J.M. et al. Avaliação de forrageiras tropicais manejadas para produção de fenoem-pé. Pesquisa Agropecuária Brasileira, v.25, n.3, p.393-407, 1990.

EUCLIDES, V.P.B.; MACEDO, M.C.M.; OLIVEIRA, M.P. Avaliação de diferentes métodos de amostragem [para se estimar o valor nutritivo de forragens] sob pastejo. Revista Brasileira de Zootecnia, v.21, n.4, p.691-701, 1992.

EUCLIDES, V.P.B.; ZIMMER, A.H.; OLIVEIRA, M.P. Evaluation of Brachiaria decumbens and Brachiaria brizantha under grazing. In: INTERNATIONAL GRASSLAND 
CONGRESS, 17., 1993, Rockhampton. Proceedings... Palmerston North: New Zealand Grassland Association, 1993. v.3, p.1997-1998.

GOMES JR., P. Composição químico-bromatológica da Brachiaria decumbens e desenvolvimento de novilhos em recria suplementados durante a seca. Viçosa, $M G$ : Universidade Federal de Viçosa, 2000. 51p. Dissertação (Mestrado em Zootecnia) - Universidade Federal de Viçosa, 2000.

GOMIDE, J.A. Morfogênese e análise de crescimento de gramíneas tropicais. In: SIMPÓSIO INTERNACIONAL SOBRE PRODUÇÃO ANIMAL EM PASTEJO, 1997, Viçosa, MG. Anais... Viçosa, MG: Universidade Federal de Viçosa, 1997. p.411-429.

GUERRERO, J.N.; CONRAD, B.E.; HOLT, E.C. et al. Prediction of animal performance on bermudagrass pasture from available forage. Agronomy Journal, v.76, p.577-580, 1984.

HODGSON J.; CLARK, D.A.; MITCHELL, R.J. Foraging behavior in grazing animals and its impact on plant communities. In: FAHEY JR., G.C. (Ed.). Forage quality, evaluation, and utilization. Madison: 1994. p.796-827.

KABEYA, K.S. Composição químico-bromatológica de gramíneas tropicais e desempenho de novilhos suplementados a pasto. Viçosa, MG: Universidade Federal de Viçosa, 2000. 74p. Dissertação (Mestrado em Zootecnia) Universidade Federal de Viçosa, 2000.

KRISHNAMOORTHY, U.; MUSCATO, T.V.; SNIFFEN, C.J. et al. Nitrogen fractions in selected feedstuffs. Journal Dairy Science, v.65, p.217-225, 1982.

LEITE, G.G.; EUCLIDES V.P. Utilização de pastagens de Brachiaria spp. In: SIMPÓSIO SOBRE MANEJO DA PASTAGEM, 1994, Piracicaba. Anais... Piracicaba: Fundação de Estudos Agrários Luiz de Queiroz, 1994. p.267-297.

LICITRA, G.; HERNANDEZ, T.M.; Van SOEST, P.J. Standardization of procedures for nitrogen fractionation of ruminant feeds. Animal Feed Science and Technology, v.57, n.4, p.347-358, 1996.

McMENIMAN, N.P. Methods of estimating intake of grazing animals. In: SIMPÓSIO SOBRE TÓPICOS ESPECIAIS EM ZOOTECNIA, 1997, Juiz de Fora. Anais... Juiz de Fora: SBZ, 1997. p.133-168.

MINSON, D.J. Forage in ruminant nutrition. San Diego: Academic Press, 1990. 483p.

NOLLER, C.H.; NASCIMENTO JR., D.; QUEIROZ, D.S. Exigências nutricionais de animais em pastejo. In: SIMPÓSIO SOBRE MANEJO DA PASTAGEM, 13., 1997, Piracicaba. Anais... Piracicaba: Fundação de Estudos Agrários Luiz de Queiroz, 1997. p.319-352.

REIS, R.A.; RODRIGUES, L.R.A.; PEREIRA, J.R.A. A suplementação como estratégia de manejo da pastagem. In: SIMPÓSIO SOBRE MANEJO DA PASTAGEM, 13., 1997, Piracicaba. Anais... Piracicaba: Fundação de Estudos Agrários Luiz de Queiroz, 1997. p.123-150.

RIBEIRO, K.G.; PEREIRA, O.G., VALADARES FILHO, S.C. et al. Caracterização das frações que constituem as proteínas e os carboidratos, e respectivas taxas de digestão, do feno de capim-tifton 85 de diferentes idades de rebrota. Revista Brasileira de Zootecnia, v.30, n.2, p.589-595, 2001.
SANTOS, E.D.G. Terminação de bovinos em pastagem de Brachiaria decumbens Stapf, durante a estação seca, alimentados com diferentes concentrados. Viçosa, MG: Universidade Federal de Viçosa, 2000. 163p. Dissertação (Mestrado em Zootecnia) - Universidade Federal de Viçosa, 2000.

SANTOS, E.D.G.; PAULINO, M.F; QUEIROZ, D.S. et al. Avaliação de pastagem diferida de Brachiaria decumbens Stapf: 2. Disponibilidade de forragem e desempenho animal durante a seca. Revista Brasileira de Zootecnia, v.33, n.1, p.214-224, 2004.

SILVA, D.J. Análise de alimentos (métodos químicos e biológicos). 2.ed. Viçosa, MG: Universidade Federal de Viçosa, 1990. $165 \mathrm{p}$.

SNIFFEN, C.J.; O'CONNOR, J.D.; Van SOEST, P.J. et al. A net carbohydrate and protein system for evaluating cattle diets: II. Carbohydrate and protein availability. Journal of Animal Science, v.70, n.12, p.3562-3577, 1992.

STOBBS, T.H. The effect of plant structure on the intake of tropical pastures. II. Differences in sward structure, nutritive value, and bite size of animals grazing Setaria anceps and Chloris gayana at various stages of growth. Australian Journal Agriculture Research, v.24, p.821-829, 1973.

THIAGO, L.R.L.; SILVA, J.M.; GOMES, R.F.C. et al. Pastejo de milheto e aveia para a recria e engorda de bovinos. Campo Grande: Embrapa Gado de Corte, 1997. 33p. (Boletim de Pesquisa, 6)

TILLEY, J.M.; TERRY, R.A. A two stage technique for the in vitro digestion of forage crops. Journal British Grassland Society, v.18, n.1, p.104-111, 1963.

Van SOEST, P.J.; ROBERTSON, J.B.; LEWIS, B.A. Symposium: carbohydrate methodology, metabolism, and nutritional implications in dairy cattle. Methods for dietary fiber, neutral detergent fiber, and nonstarch polysaccharides in relation to animal nutrition. Journal of Animal Science, v.74, n.10, p.3583-3597, 1991.

VIEIRA, R.A.M. Simulação da dinâmica de nutrientes no trato gastrintestinal: aplicação e validação de um modelo matemático para bovinos a pasto. Viçosa, MG: Universidade Federal de Viçosa, 1998. 91p. Tese (Doutorado em Zootecnia) Universidade Federal de Viçosa, 1998.

VITORI, A. Produção e determinação das frações de proteínas e carboidratos de gramíneas tropicais. Campos dos Goytacazes: Universidade Estadual do Norte Fluminense, 1998. 79p. Dissertação (Mestrado em Zootecnia) - Universidade Estadual do Norte Fluminense, 1998.

Recebido em: 03/05/02

Aceito em: 19/05/03 